Jurnal Pengajian Melayu - JOMAS, Jilid 31, 2020: 61-75

\title{
TINGKAH LAKU PENIAGA WANITA MELAYU DALAM TALIAN: SOROTAN LITERATUR DAN TEORI
}

\author{
(BEHAVIOUR OF FEMALE MALAY ENTREPRENEURS: \\ LITERATURE REVIEW AND THEORY)
}

\author{
Norsafani Maisarah Mohd Nawi \\ Akademi Pengajian Melayu, Universiti Malaya \\ Malaysia \\ norsafanimaisarahmohdnawi@yahoo.com \\ Nur Yuhanis Mohd Nasir \\ Akademi Pengajian Melayu, Universiti Malaya \\ Malaysia \\ yuhanis83@um.edu.my

\section{Kim Keum Hyun} \\ Fakulti Bahasa dan Linguistik, Universiti Malaya \\ Malaysia \\ korea@um.edu.my
}

Received: 19 Januari 2019; Accepted: 9 November 2020

\begin{abstract}
The development of information and communications technology (ICT) has created new opportunities for sharing and gathering of knowledge in society, especially in the field of business. The conversion of conventional businesses to online entities has also introduced positive changes to the business world, especially for female Malay entrepreneurs. Overall, online businesses utilise the Internet to conduct their activities. This article aimed to discuss the development of literature, be it in the form of research, books or articles, and theories with regards to the factors of involvement, successes, failures, challenges and support schemes available for female Malay entrepreneurs. In this study, document analysis using a literary research approach was conducted. Findings revealed that there is a substantial amount of writing, ideas and discussions produced by both scholars and the government on the issue at hand.
\end{abstract}

Keywords: Literature review, theory, involvement factors, success and failure factors, business challenges, role of support schemes, female Malay entrepreneurs.

e ISSN 2735 - 1904

https://doi.org/10.22452/JOMAS.vol31no1.5 


\begin{abstract}
Abstrak
Perkembangan Teknologi Maklumat dan Komunikasi (TMK) telah membawa peluang-peluang baru untuk perkongsian dan pengumpulan pengetahuan dalam masyarakat terutamanya dalam bidang perniagaan. Perubahan daripada perniagaan konvensional kepada perniagaan dalam talian membawa perubahan positif kepada dunia perniagaan terutamanya kepada peniaga wanita Melayu dalam talian, secara keseluruhan perniagaan dalam talian menggunakan medium internet dalam keseluruhan aktiviti. Artikel ini membincangkan satu perkembangan penulisan, sama ada dalam bentuk penyelidikan, buku, artikel dan sebagainya dalam membahaskan sorotan kajian serta landasan teori berkaitan faktor penglibatan, faktor kejayaan dan kegagalan, cabaran yang didepani dan juga peranan skim sokongan kepada peniaga wanita Melayu yang menggunakan medium perniagaan dalam talian. Kajian ini dilakukan dengan menggunakan metode analisis dokumen dengan mengambil pendekatan kajian kepustakaan. Hasil sorotan kajian dan teori yang didasarkan dalam bidang perniagaan, mendedahkan bahawa telah banyak penulisan, lontaran idea dan perbincangan berkenaan perkara ini telah dibincangkan.
\end{abstract}

Kata kunci: sorotan kajian, teori, faktor penglibatan, faktor kejayaan dan kegagalan, cabaran perniagaan, peranan skim sokongan, peniaga wanita Melayu dalam talian.

\title{
Pengenalan
}

Perniagaan dalam talian merupakan satu perkembangan dalam bidang perniagaan yang disebabkan oleh perkembangan teknologi maklumat dan komunikasi (TMK) (selepas ini akan digunakan perkataan TMK) di dunia. Proses keseluruhan penggunaannya melibatkan medium internet yang dikenali sebagai perniagaan berkonsepkan dalam talian yang menggunakan media sosial sebagai medium perniagaan utama. Perkembangan perniagaan dalam talian ini merupakan platform terbaik yang digunakan untuk menjalankan aktiviti perniagaan dan pemasaran masa kini kerana menawarkan pelbagai kemudahan kepada penggunanya. Hal ini dapat dibuktikan dengan peningkatan jumlah penglibatan peniaga dalam talian saban tahun dan pelbagai medium baru bagi perniagaan dalam talian. Hal ini dibuktikan dengan statistik terkini menunjukkan seramai 53,285 peniaga dalam talian yang berdaftar dengan Suruhanjaya Syarikat Malaysia (SSM) sehingga bulan Julai 2017 (Suruhanjaya Syarikat Malaysia, 2017).

Oleh sebab terdapat pelbagai kelebihan dan kemudahan yang ditawarkan dalam talian, Berjaya menarik perhatian masyarakat terutamanya dalam kalangan wanita Melayu terlibat dalam perniagaan ini sama ada secara kecil-kecilan atau besar-besaran. Penglibatan wanita dalam bidang perniagaan secara talian menyebabkan berlaku peningkatan yang ketara disamping, kewujudan pelbagai aplikasi dalam talian seperti blog, Facebook, Instagram, Telegram dan juga aplikasi e-perniagaan (Nor Fazilah Noor Din \& Hishamudin Isam, 2019) untuk meningkatkan capaian urusan perniagaan dan juga memudahkan urusan jual beli produk. Pernyataan ini dibuktikan dengan penglibatan lebih 80 peratus daripada usahawan berdaftar di bawah Persatuan Pedagang dan Pengusaha Melayu Malaysia (PERDASAMA) adalah wanita (BH Online, 2017).

Justeru, perkembangan TMK dan peningkatan peniaga wanita Melayu dalam talian mendorong penulisan artikel ini. Elemen yang dikaji adalah berdasarkan kajian sorotan literatur dan teori berkaitan tingkah laku perniagaan dalam talian oleh pengkaji-pengkaji terdahulu daripada faktor penglibatan, faktor pemangkin kepada kejayaan dan kegagalan, cabaran yang dihadapi

e ISSN 2735 - 1904

https://doi.org/10.22452/JOMAS.vol31no1.5 
dan skim sokongan yang membantu perniagaan dalam talian yang dijalankan. Aspek-aspek ini dianggap amat penting untuk dikupas memandangkan ianya akan menjadi penentu utama dalam mengukur pemerkasaan peniaga wanita dalam menghadapi perubahan struktur perniagaan ini.

\section{Bidang Perniagaan dan Peniaga Wanita Melayu dalam Talian}

Tradisi wanita yang melibatkan diri dalam dunia perniagaan memang banyak berlaku di negaranegara Asia Tenggara dan Afrika. Di Asia Tenggara, ruang perniagaan banyak dikuasai oleh wanita sehingga mewujudkan suatu pola perniagaan dalam kalangan wanita. Kewujudan lebihan daripada peta subsistem menjadi faktor utama dalam menentukan penglibatan wanita dalam perniagaan yang banyak bermula di pasar. Aktiviti perniagaan ini masih berlangsung sehingga hari ini dengan pelbagai perubahan mengikut arus perkembangan zaman (Norhayati Ab. Rahman, 2010).

Rentetan itu, perubahan zaman dan perkembangan teknologi telah membawa perubahan yang drastik dalam landskap perniagaan di dunia. Hasil perkembangan teknologi telah membawa transformasi daripada perniagaan konvensional kepada perniagaan dalam talian (e-dagang). E-dagang di dunia telah bermula sejak awal tahun 1970-an lagi, yang mana pada waktu itu penggunaan aplikasi masih terbatas kepada perusahaan kecil sahaja. Di Malaysia, Ismail Zain telah membuka lembaran baru sekaligus membuka pintu kepada dunia digital dalam bidang perniagaan di negara ini serta penubuhan Malaysia Super Corridor (MSC), TMK dilihat berupaya memacu Malaysia menjadi sebuah negara yang berdaya maju dan kompetitif sesuai dengan cabaran globalisasi dan era teknologi maklumat (Sharulnizam Ramli, et al., 2015).

Namun begitu, penggunaan perniagaan berkonsepkan dalam talian di Malaysia agak lewat berkembang, iaitu mula berkembang sekitar tahun 2000. Walaupun lewat berkembang, berlakunya perkembangan yang positif dengan jumlah penglibatan kian meningkat saban tahun. Selari dengan kajian oleh Multimedia Universiti Malaysia menyatakan bahawa e-dagang memperoleh potensi pertumbuhan yang tinggi disebabkan oleh peningkatan pesat dalam bilangan pengguna komputer dan perkhidmatan internet yang lebih laju setiap tahun.

Lantaran daripada itu, fenomena wanita yang menceburkan diri dalam perniagaan secara talian telah memberi impak yang besar dalam kehidupan golongan ini (Fortune Magazine, 2012). Pernyataan ini dibuktikan oleh Siti Haniah (2015), menyatakan perniagaan dalam talian atau e-dagang merupakan salah satu medium perniagaan terkini yang banyak diaplikasikan pada masa kini dengan kehadiran pelbagai produk yang diasaskan oleh wanita Melayu dalam pelbagai bidang perniagaan terutamanya dalam bidang kecantikan dan kesihatan seperti K' Hermosa, AR Beauty, Sobella, Ekora Beauty dan banyak lagi produk yang diasaskan oleh wanita Melayu. Ini juga terbukti dengan lebih 80 peratus daripada usahawan berdaftar di bawah Persatuan Pedagang dan Pengusaha Melayu Malaysia (PERDASAMA) adalah wanita. Statistik memperlihatkan perkembangan positif minat wanita dalam dunia perniagaan yang memberikan peluang untuk menjana pendapatan lumayan (PERDASAMA, 2017).

Justeru, perkembangan dalam penggunaan internet masa kini telah membawa satu perubahan yang besar kepada dunia perniagaan kerana peluang untuk memperkembangkan perniagaan terbuka luas dengan adanya media sosial (Erickson, et al., 2010). Peningkatan ini menunjukkan bahawa

e ISSN 2735 - 1904

https://doi.org/10.22452/JOMAS.vol31no1.5 
wanita di Malaysia jelas mempunyai komitmen untuk memanfaatkan peluang-peluang dalam perdagangan dan industri, hasil daripada proses perindustrian dan pembangunan ekonomi. Oleh yang demikian, pihak-pihak yang terbabit seperti Kementerian Pembangunan Wanita, Keluarga dan Masyarakat, Persatuan Usahawan Wanita Bumiputera (USAHANITA), Dewan Perniagaan Melayu, Kementerian Pembangunan Usahawan dan badan-badan organisasi lain telah berusaha untuk membantu golongan wanita, khususnya wanita Melayu dalam melahirkan lebih ramai usahawan-usahawan wanita bumiputera yang bukan sahaja berjaya di dalam negara, bahkan di peringkat antarabangsa.

\section{Kaedah Kajian}

Kajian ini menggunakan metode pengumpulan data melalui analisis kandungan dokumen. Pengumpulan maklumat melalui pembacaan kepustakaan termasuklah membuat rujukan dari buku, tesis, artikel jurnal, kertas persidangan/ seminar, carian di internet dan seumpamanya sama ada dalam bahasa Melayu dan bahasa Inggeris. Pendekatan ini bersesuaian untuk mendapatkan maklumat yang mencukupi dalam kajian literatur dan teori berkaitan dengan tingkah laku peniaga wanita Melayu secara talian di Malaysia.

\section{Aspek Tingkah Laku Perniagaan dalam Talian}

\section{Faktor Penglibatan}

Faktor penglibatan merupakan aspek yang penting bagi seseorang individu untuk berkecimpung dalam dunia perniagaan. Analisis penglibatan berkaitan faktor dalaman oleh Iriz \& Dezhi (2014), mendedahkan bahawa perasaan yang dialami sama ada sedih, gembira dan sebagainya memenuhi kepuasan menggunakan media TMK bagi urusan perniagaan dalam talian disamping, emosi mempengaruhi kelancaran perniagaan yang dijalankan. Namun begitu, kajian oleh Afzal Hossain, et al. (2018), mendedahkan faktor kemahiran dalaman seperti pengalaman perniagaan, pelan perniagaan, pengetahuan, minat dan hobi, keuntungan, latihan perniagaan, dan sokongan dari institusi kewangan mempengaruhi penglibatan wanita sebagai usahawan dalam sektor PKS.

Bagi faktor penglibatan luaran pula, menurut Zaharin, et al. (2014), beliau mendedahkan faktor peribadi dan keluarga, faktor pendidikan dan pengetahuan serta peranan kerajaan dan penglibatanmasyarakatmenjadisebab penglibatan. Faktor-faktorpendorong tersebutmempengaruhi tingkah laku peniaga dalam talian terutamanya bagi meningkatkan kewangan untuk mendapatkan lebihan pendapatan dan mencapai keselamatan kewangan. Namun begitu, dapatan daripada kajian Comilla (2018), mendapati bahawa perubahan teknologi dan kestabilan ekonomi mempengaruhi keputusan untuk terlibat dalam perniagaan. Hal ini kerana, perkembangan teknologi dan faktor ekonomi merupakan pemangkin utama untuk seseorang individu terlibat dalam perniagaan secara talian. Pernyataan ini dibuktikan oleh kanyataan daripada Tan Sri Shahrizat Abdul Jalil bahawa penglibatan peniaga wanita dalam talian dijangka meningkat kepada 23 peratus menjelang 2020 (Bernama, 2018).

Selain faktor penglibatan dalaman dan luaran, terdapat faktor-faktor lain yang mempengaruhi penglibatan peniaga dalam talian. Menurut Kim Ling Geraldine Chan, et al. (2015), mendapati bahawa peningkatan penglibatan peniaga dalam talian adalah disebabkan kepopularan 
dan mendapat keuntungan yang tinggi serta mudah untuk dijalankan. Kajian oleh pengkaji ini bersesuaian dengan kehendak semasa kerana perniagaan dalam talian kian popular dalam kalangan peniaga wanita Melayu dan pembeli kerana kaedah jual beli barangan adalah lebih mudah dan cepat berbanding jual beli secara kaedah konvensional.

Sebagai tambahan, kajian oleh Azlizan Talib, et al. (2017), menyatakan bahawa perniagaan dalam talian memberi implikasi positif dalam mempengaruhi cara hidup masyarakat, terutamanya dalam kalangan peniaga wanita dengan cara menjimatkan masa pengguna dan turut memberi implikasi negatif dengan mengurangkan interaksi sosial dalam kalangan masyarakat. Kajian ini mendedahkan bahawa walaupun perniagaan dalam talian mempunyai pelbagai kelebihan, namun boleh mengurangkan interaksi sosial kerana hubungan yang dijalankan hanya secara dalam talian dan tidak bersemuka seperti yang berlaku dalam perniagaan secara konvensional.

Pernyataan tersebut tidak selari dengan dapatan daripada Suriatie \& Nor Aishah (2017), mereka menyatakan variasi dalam cabang media sosial membolehkan pengguna internet khususnya mempunyai pilihan untuk berkomunikasi antara satu sama lain. Oleh itu, usahawan wanita melihat perkara ini sebagai satu peluang untuk mendekati sasaran pelanggan walaupun tanpa bersemuka. Mereka perlu mempunyai kemahiran interpersonal bagi mendekati dan terus berhubungan dengan individu yang terlibat dalam perniagaan secara talian yang dijalankan. Justeru, penglibatan peniaga wanita, khususnya peniaga wanita Melayu dalam talian memberikan implikasi yang positif sebagai ejen perubahan dalam kehidupan mereka untuk lebih maju dan berjaya sehingga ke peringkat global.

\section{Faktor Kejayaan dan Kegagalan}

Faktor kejayaan dan kegagalan diukur berdasarkan analisis SWOT. Menurut Rangkuti, F. (2000), analisis SWOT adalah suatu proses untuk mengenal pasti faktor dalaman dan faktor luaran yang mempengaruhi sesuatu tindakan atau pelaksanaan suatu strategi yang akan dilakukan oleh sesebuah organisasi dalam mencapai matlamat, visi dan misi organisasi.

Bagi analisis kekuatan (strength), kajian oleh Gusniar N. I. et al. (2014), mendedahkan keupayaan membina dan memantapkan jalinan hubungan sosial dengan pelanggan, ejen, pembekal dan pesaing merupakan kekuatan yang perlu ada bagi mencapai kejayaan kerana perniagaan dalam talian memerlukan komunikasi keseluruhan secara dalam talian. Selain itu, Kim Ling Geraldine Chan, et al. (2015), menyatakan kejayaan peniaga wanita disebabkan mempunyai sifat-sifat keusahawanan seperti kreatif, mempunyai keazaman dan keupayaan, peramal keupayaan, menjadi ghairah dengan perniagaan, berorientasikan pelanggan, menunjukkan integriti dan kesediaan berkongsi.

Bagi faktor kekurangan (weakness), kajian oleh Nor Aini (2008), mendedahkan kebanyakan perniagaan dalam talian terbengkalai separuh jalan kerana kebanyakan peniaga dalam talian mempunyai personaliti yang mudah mengalah. Selain personaliti, kelemahan dalam pemasaran seperti kandungan dan ayat pemasaran yang tidak menarik mengundang kepada kegagalan dalam perniagaan dalam talian kerana menurut $\mathrm{Hu}$, et al. (2011) maklumat yang pertama dilihat oleh pelanggan adalah berkaitan jenama, produk atau perkhidmatan yang berkaitan dengan penawaran produk dari sesebuah syarikat. Justeru itu, kurangnya kemahiran dalam menarik perhatian pelanggan

e ISSN 2735 - 1904

https://doi.org/10.22452/JOMAS.vol31no1.5 
akan membawa kepada kegagalan. Ini selari dengan kajian oleh Lovett (2011), kurangnya interaksi dalam talian seperti jumlah pelawat dan kepuasan pelanggan mempengaruhi kepada kegagalan sesebuah perniagaan dalam talian.

Bagi faktor peluang (opportunity), kajian oleh Moloi (2014), mendapati bahawa inovasi dalam pemasaran, kreatif dan peka dengan persekitaran perniagaan merupakan ciri-ciri personaliti usahawan yang berjaya. Sementara itu, kajian oleh Nor Azira Ayobi, et al. (2016), mendedahkan faktor modal insan dari sudut pendidikan dan latihan, pengalaman, sokongan sosial dan aspek kreativiti merupakan faktor kejayaan kepada peniaga dalam talian. Peluang dari segi pendidikan dan latihan memainkan peranan penting dalam memperkembangkan potensi individu untuk berjaya dalam bidang yang diceburi.

Bagi analisis ancaman (threat) pula, kajian oleh Nurdin, et al. (2014), menunjukkan ancaman perniagaan dalam talian bergantung kepada beberapa faktor seperti risiko perniagaan, persaingan, modal, bekalan dan sebagainya. Selain itu, kajian oleh Afroze, et al. (2014), mendapati bahawa ancaman juga terjadi disebabkan diskriminasi jantina, buta huruf dan kurang pengetahuan, tidak ada sokongan program latihan dan teknikal, kekurangan pengalaman serta kaedah pengurusan perniagaan yang tidak efisien menyebabkan kegagalan. Justeru, peniaga wanita Melayu dalam talian perlu mengubah personaliti luaran dan dalaman supaya dapat meningkatkan keberkesanan perniagaan dalam talian yang dijalankan.

\section{Cabaran Perniagaan dalam Talian}

Setiap perkara yang dilakukan tidak akan terlepas daripada menghadapi sebarang cabaran atau halangan seperti peniaga dalam talian juga tidak terlepas daripada menghadapinya. Walaupun bilangan peniaga yang berkecimpung dalam perniagaan ini meningkat saban tahun, namun menurut kajian hanya 15 peratus sahaja yang berjaya, manakala 85 peratus lagi akan menemui kegagalan sama ada dalam tempoh dua atau tiga bulan selepas mereka menjalankan perniagaan.

Berdasarkan dapatan kajian daripada Suhana Safari \& Maisharah Ngusman (2010), aspek pasaran dan persaingan menjadi cabaran yang dihadapi oleh peniaga wanita dalam talian, antaranya persaingan dari pasaran luar dan permasalahan dalam menghadapi syarikat palsu. Hal ini demikian kerana terdapat pelbagai platform pemasaran perniagaan dalam talian yang memasarkan produk yang sama menyebabkan persaingan antara peniaga adalah amat sengit.

Menurut Cheung \& Lee (2010), perniagaan yang menggunakan medium e-pemasaran sangat mementingkan maklumat produk yang lengkap, terkini dan tersusun bagi mengekalkan kepercayaan pelanggan dan mengatasi masalah penipuan daripada pelanggan kerana perniagaan ini tidak melibatkan interaksi secara langsung antara penjual dan pengguna dalam erti kata lain tidak bersemuka. Hal ini selari dengan kajian oleh Usry Norie (2017), menyatakan cabaran yang perlu ditempuh bagi peniaga dalam talian adalah cabaran memperkenalkan jenama (brand), menguruskan 'noise' yang muncul di laman sosial, cabaran mengendalikan laman sosial dan tidak mempunyai bajet yang cukup.

Sebaliknya, kajian oleh Alauddin Sidal (2014), menunjukkan cabaran membawa impak yang positif. Beliau mendapati peniaga wanita Melayu yang berjaya menghadapi cabaran-cabaran

e ISSN 2735 - 1904

https://doi.org/10.22452/JOMAS.vol31no1.5 
dalam perniagaan mempunyai daya tahan yang tinggi dan mempamerkan prestasi yang baik dalam perniagaan. Penemuan kajian ini memperlihatkan bahawa peniaga wanita yang berjaya dalam perniagaan dan mampu bertahan menghadapi cabaran perniagaan mempunyai kepakaran dan komitmen yang tinggi dalam perniagaan secara talian yang dijalankan.

\section{Skim Sokongan Perniagaan}

Skim sokongan perniagaan kepada pembangunan masyarakat, khususnya pembangunan ekonomi merupakan perkara yang dititikberatkan bagi menjamin kualiti hidup rakyat. Justeru, salah satu skim sokongan kerajaan adalah melalui pembangunan perniagaan dalam talian.

Menurut Yahya (2014), terdapat beberapa agensi yang bertanggungjawab dalam pembangunan usahawan dan bakal-bakal usahawan bumiputera di Malaysia, iaitu Tabung Ekonomi Usaha Niaga (TEKUN), Majlis Amanah Rakyat (MARA), UDA Holdings Bhd, Bank Pembangunan, SME Bank, Perbadanan Nasional Berhad (PNS), Bank Rakyat, Jabatan Pembangunan Koperasi (JPK), Maktab Kerjasama Malaysia (MKM) dan Syarikat Pembangunan Ekonomi Negeri (SEDCs). Berdasarkan kajian oleh Radiah, et al. (2009) ke atas usahawan di kawasan luar bandar di Malaysia bawah program 'One-District-One Industry" (ODOI), menunjukkan kejayaan dan kegagalan usahawan adalah berdasarkan bantuan latihan, kualiti diri, persekitaran luar, polisi kerajaan, pembekal bahan mentah, sokongan pasaran oleh kerajaan, kesampaian pasaran, jaringan sosial, perkhidmatan dan tenaga kerja.

Selain itu, Norsela \& Nurul Ilyana (2016), pula mendapati kesan penyertaan latihan dan hasil pembelajaran yang diperolehi secara tidak langsung dapat meningkatkan ekonomi bagi PKS dengan memperkembangkan lagi pasaran produk ke peringkat antarabangsa. Perkara ini selari dengan kajian oleh Chang (2010) yang mengatakan bagi memenuhi objektif pembangunan ekonomi, institusi mempunyai peranan dalam memberi peluang pendidikan dan latihan, pelaburan dalam infrastruktur, perindustrian atau pemberian bantuan kewangan dan bukan kewangan yang secara tidak langsung merangsang kepada pembangunan ekonomi. Namun begitu, kajian oleh Nor Hayati Sa'at \& Abdul Rahman Embong (2015) mendapati pemerkasaan daripada agen pembangunan bukan pemerintah seperti YDSM bagi bantuan kewangan mendedahkan keputusan yang positif kepada peserta ibu tunggal kerana mereka dapat meningkatkan kemahiran, disamping dapat meningkatkan taraf hidup keluarga.

Sebagai tambahan, kajian oleh Ummi Munirah Syuhada Mohamad Zan, et al. (2017), mendapati modal kewangan dan motivasi daripada TEKUN mempunyai hubungan yang kuat dengan kejayaan usahawan wanita TEKUN. Selari dengan kajian oleh Muhammad Rafiq Abdullah Husmin, et al. (2016) mendapati pembiayaan mikro merupakan antara teras dan fokus kerajaan pada masa kini yang bertujuan untuk membela nasib semua golongan rakyat yang memerlukan bantuan agar mereka dapat bersama-sama menyertai arus pembangunan pesat negara. Justeru itu, dapatan kajian terdahulu menunjukkan pentingnya sokongan daripada pihak berwajib dalam meningkatkan ekonomi di Malaysia terutamanya kepada golongan peniaga wanita Melayu. 


\section{Teori Kajian Tingkah laku Perniagaan dalam Talian}

Teori adalah satu sistem idea yang bertujuan untuk menerangkan sesuatu perkara berdasarkan idea-idea umum yang bebas daripada perkara yang diterangkan. Hal ini demikian kerana alat penerangan dan tafsiran yang membolehkan seseorang memahami sesuatu perkara dan menghadkan pemahamannya berdasarkan konteks kajiannya (Ott \& Mack, 2014). Disebabkan perniagaan secara talian adalah bidang yang inter-disiplin, terdapat teori-teori yang dicerap daripada bidang yang berbeza yang akhirnya membentuk pelbagai acuan kajian tingkah laku perniagaan dalam talian. Subtopik berikut membincangkan beberapa teori yang popular dan kerap digunakan dalam kajian tingkah laku perniagaan dalam talian.

\section{Teori Tindakan Bertujuan (Theory of Reasoned Action-TORA)}

Teori tindakan bertujuan adalah teori yang sesuai diaplikasikan bagi mengkaji sebab penglibatan perniagaan dalam talian. TORA telah dibina oleh Fishbein, M. \& Ajzen, I. (1980). Teori ini menjelaskan bahawa sikap terhadap tingkah laku bermula dengan kepercayaan tentang kesan tingkah laku tersebut. Oleh hal demikian, sikap merupakan penentu kepada sesuatu bentuk tingkah laku. Ajzen \& Fishbein (1980), memutuskan bahawa sikap dan tingkah laku mengandungi empat elemen, iaitu tindakan yang khusus, sasaran sesuatu tindakan tersebut dilakukan, konteks di mana tindakan tersebut dilakukan dan waktu tindakan tersebut dilakukan. Teori ini adalah berdasarkan andaian bahawa sikap seseorang akan terbentuk daripada kepercayaan tentang ciri-ciri dan tanggapannya terhadap ciri tersebut.

Oleh itu, teori ini mengandungi beberapa pemboleh ubah seperti keazaman atau kemahuan tingkah laku, niat untuk melakukan tingkah laku tersebut, sikap terhadap tingkah laku tersebut, nilai kepercayaan seseorang terhadap tanggapan orang lain terhadap apa yang perlu dilakukannya dan dorongan untuk memenuhi jangkaan orang lain. Kesan kepada tingkah laku ini mungkin bersifat utilitarian, iaitu pengalaman terhadap ganjaran dan dendaan, atau bersifat nomatif, iaitu persepsi orang lain bagi membenarkan tingkah laku ataupun tidak.

Pernyataan ini selari dengan kajian oleh Norashidah Hashim, et al. (2009) yang mendasari kerangka berasaskan kepada teori tindakan bertujuan, Hasil kajian mendapati usahawan wanita Melayu Industri Kecil Sederhana (IKS) mendedahkan elemen kemahuan dan kebolehan merupakan taksonomi kesediaan bagi terlibat dalam bidang keusahawanan.

\section{Teori Tingkah laku Terancang (Theory of Planned Behavior-TPB)}

Teori tingkah laku terancang adalah teori yang sesuai diaplikasikan bagi mengkaji strategi dan halangan perniagaan dalam talian. TPB telah dibangunkan oleh Ajzen (1991), dan telah digunakan secara meluas dalam meramalkan tingkah laku seseorang individu terhadap sesuatu perkara. Teori ini secara umumnya merangkumi sikap individu, norma subjektif daripada pihak-pihak yang berkepentingan kepada seseorang individu dan tanggapan tingkah laku. 
Di samping itu, keinginan individu sebagai faktor motivasi berdasarkan Ajzen (1991), turut mempengaruhi keputusan seseorang individu yang bergantung kepada tiga elemen utama, iaitu sikap atau nilai peribadi yang merujuk kepada tahap sokongan terhadap sesuatu kelakuan, norma subjektif, iaitu tekanan sosial yang mendorong seseorang untuk melakukan sesuatu perkara atau tidak melakukannya dan tanggapan kawalan tingkah laku, iaitu sejauh mana seseorang itu berupaya untuk mengawal tingkah laku mereka. Ajzen telah merumuskan keterangan-keterangan di atas dalam Rajah 1.

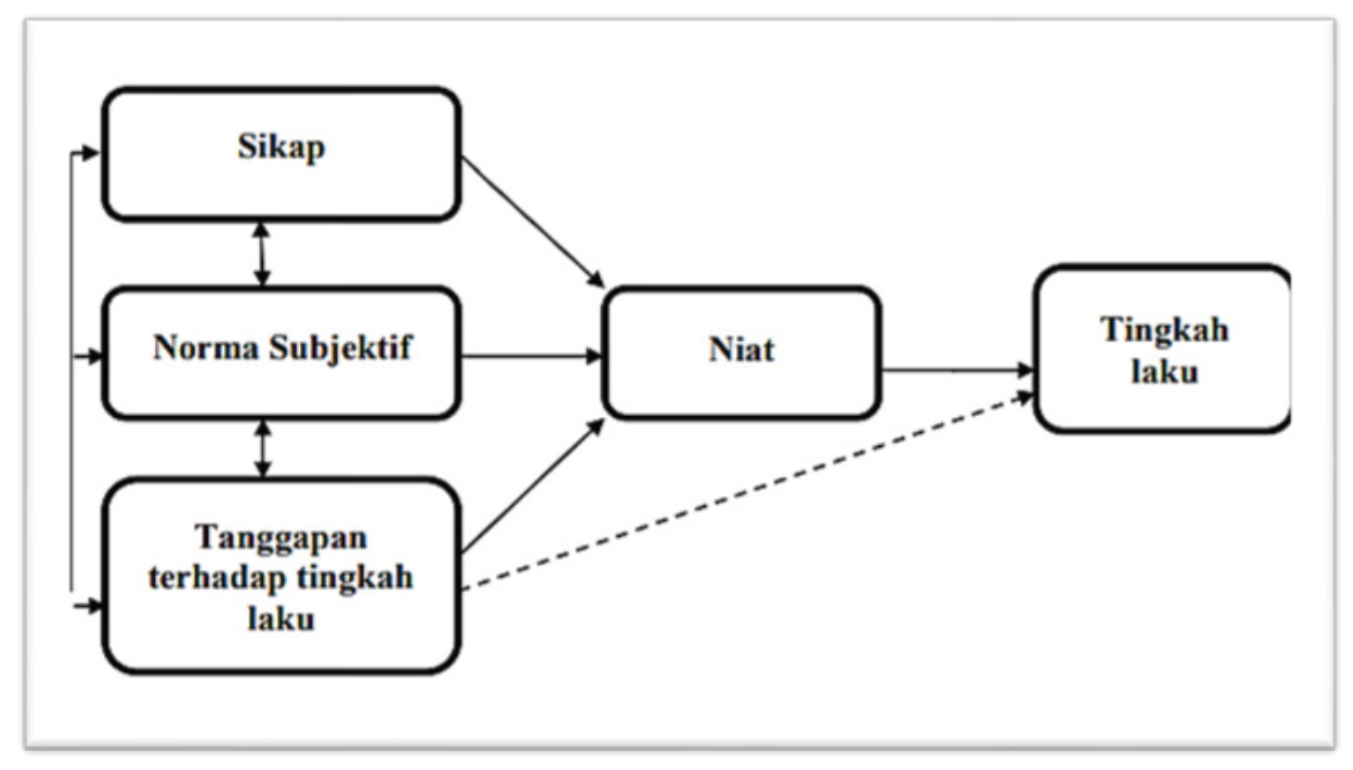

Rajah 1: Teori tingkah laku terancang yang dikemukakan oleh Ajzen (1991).

Selari dengan kajian oleh Zaidatol \& Hisyamuddin (2010), teori ini fokus kepada keinginan sebagai percubaan untuk melaksanakan sesuatu perkara atau aktiviti yang dirancang kepada keadaan yang sebenar. Di samping itu, teori ini juga menganggap keinginan adalah faktor motivasi yang mempengaruhi kelakuan seseorang individu untuk mencuba sesuatu perkara atau aktiviti yang dirancang atas usaha mereka sendiri. Teori ini juga dibuktikan oleh Mohd Shahrir Abdullah (2015), yang menunjukkan setiap faktor keusahawanan yang dikaji, iaitu dorongan, kepimpinan, kemahiran, motivasi, dan pengalaman adalah sangat mempengaruhi tingkah laku keusahawanan. Bagi faktor sikap, kurang mempengaruhi tingkah laku keusahawanan serta faktor minat dan kepimpinan pula tidak mempengaruhi tingkah laku keusahawanan. 


\section{Teori Gabungan Penerimaan dan Penggunaan Teknologi (Unified Theory of}

\section{Acceptance and Use Technology-UTAUT)}

Teori ini sesuai bagi cabaran dan skim sokongan bagi perniagaan dalam talian. Teori UTAUT telah dibina oleh Venkatesh, Morris, Davis \& Davis (2003), yang menekankan empat gagasan, iaitu jangkaan prestasi, jangkaan usaha, pengaruh sosial dan keadaan kemudahan. Empat pemboleh ubah bersandar, iaitu jantina, umur, pengalaman dan penggunaan secara sukarela telah dikemukakan sebagai faktor penyederhana kepada hubungan antara empat gagasan tersebut dengan niat penggunaan dan tingkah laku.

Model UTAUT melibatkan gabungan lapan teori utama dan telah diuji menggunakan set data dunia sebenar yang besar, iaitu (1) Teori Tindakan Bersebab (TRA), (2) Model Penerimaan Teknologi (TAM), (3) Model Motivasi (MM), (4) Teori Tingkah Laku Terancang (TPB), (5) Gabungan Model Penerimaan Teknologi dan Teori Tingkah Laku Terancang (C-TAM-TPB), (6) Model Penggunaan PC (MPCU), (7) Teori Difusi Inovasi (IDT), dan (8) Teori Kognitif Sosial (SCT). Rajah 2 menunjukkan model bagi UTAUT.

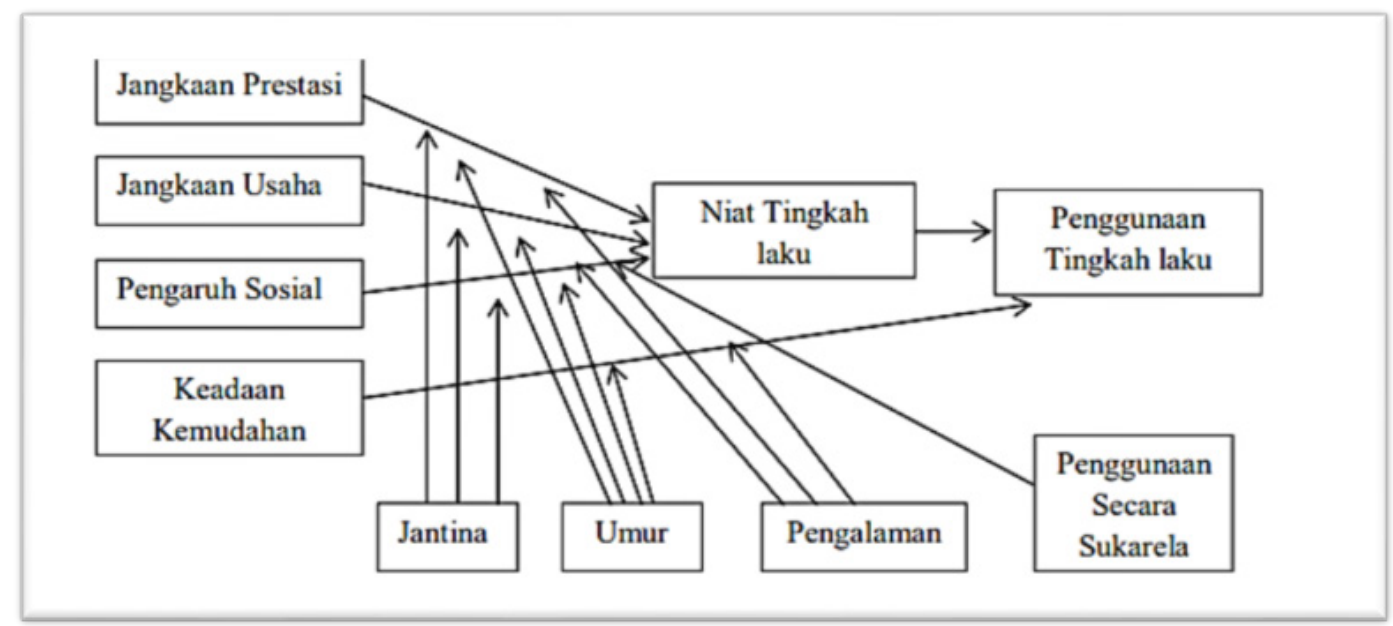

Rajah 2: Model Teori Gabungan Penerimaan dan Penggunaan Teknologi (UTAUT)

Teori ini selari dengan kajian oleh Azilahwati Adam, et al. (2019), yang bersandar kepada Teori Gabungan Penerimaan dan Penggunaan Teknologi (UTAUT) mendedahkan bahawa jangkaan prestasi memberi kesan yang signifikan terhadap niat usahawan PKS untuk menggunakan s-dagang. Namun, jangkaan prestasi mempunyai hubungan negatif yang signifikan dengan niat untuk menggunakan media sosial dalam kajian. Ini bermakna usahawan PKS percaya bahawa s-dagang mampu meningkatkan prestasi perniagaan mereka. 


\begin{abstract}
AIDA Model
AIDA Model (2005), adalah model yang dapat dikaitkan dengan pendekatan penggunaan medium e-pemasaran dan prestasi jualan dalam kalangan peniaga dalam talian. Ferrel, Hartline \& Michael (2005), menerusi model AIDA menjelaskan bahawa pendekatan yang digunakan membantu dalam kejayaan perniagaan dalam talian. Model AIDA adalah salah satu teori dasar yang banyak digunakan dalam dunia pemasaran sebagai proses penjualan sesebuah produk. Menurut model ini, alat promosi harus menarik perhatian, mendapatkan dan mendorong minat, membangkitkan keinginan, dan menghasilkan tindakan. Teori keputusan pembelian dalam model AIDA dijelaskan dalam empat tahap:
\end{abstract}

\title{
i. Tahap Pengaruh Perhatian (Attention)
}

Tahap pengaruh perhatian adalah tahap di mana individu menarik perhatian para pelanggan mengenai produk yang ada. Pada tahap ini, pendekatan yang digunakan ialah melalui promosi yang dilakukan dengan menggunakan media sosial, media cetak, radio, televisyen atau jaringan personal lain.

\section{ii. $\quad$ Tahap Tarikan (Interest)}

Setelah berjaya meraih perhatian dan tarikan pelanggan, seseorang usahawan sentiasa mengemas kini dan memberi khidmat selepas jualan. Pada tahap ini, individu lebih kepada memberi maklumat dan informasi mengenai produk dan menggunakan kaedah pemujukan supaya para pelanggan membeli produk yang ditawarkan.

\section{iii. Tahap Berhasrat/Berniat (Desire)}

Pada tahap ini, seseorang usahawan memberi tawaran yang sangat istimewa kepada pelanggan sehingga pelanggan tidak dapat menolak tawaran yang diberikan sebagai contoh jualan murah secara besar-besaran. Pendekatan ini digunakan supaya timbul keinginan dan hasrat daripada para pelanggan untuk membeli produk.

\section{iv. Tahap Memutuskan untuk Tindakan (Action)}

Seseorang pelanggan mengambil tindakan untuk mula membeli produk apabila tawaran telah diberikan kepada penjual. Pada tahap ini tindakan daripada pelanggan membeli barangan dan produk memberi kesan kepada peningkatan prestasi jualan sesebuah perniagaan. 


\section{v. Tahap kepuasan (Satisfaction)}

Tahap akhir ini juga penting, iaitu para pelanggan berpuas hati dengan produk yang telah diberikan dan akhirnya memutuskan untuk mengulang membeli produk yang dijual.

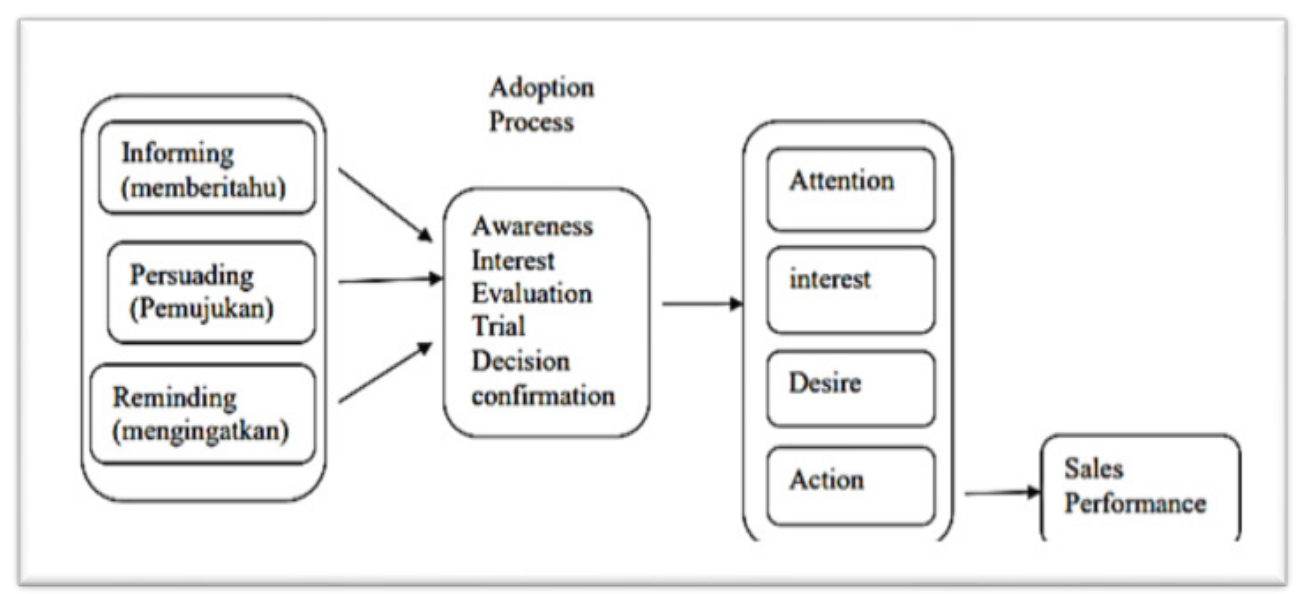

Rajah 3: Model AIDA

Model ini dapat dibuktikan dengan kajian oleh Suriatie Mohd Yunus \& Nor Aishah Buang (2016), yang membincangkan pendekatan penggunaan medium e-pemasaran yang digunakan oleh peniaga wanita dalam meningkatkan prestasi jualan mendapati penggunaan tiga jenis pendekatan, iaitu pendekatan memberitahu (informing), memujuk (persuading) dan mengingatkan (reminding) merupakan elemen yang penting bagi meningkatkan prestasi jualan dengan penggunaan medium e-pemasaran.

\section{Analisis dan Perbincangan Sorotan Literatur dan Teori}

Berdasarkan dapatan kajian oleh penyelidik terdahulu berkaitan faktor penglibatan mendapati bahawa faktor dalaman seperti minat, hobi dan motivasi, jaringan usahawan dan inovasi merupakan antara pendorong penglibatan peniaga wanita Melayu dalam talian. Seterusnya, faktor luaran yang menjadi penyebab penglibatan ialah faktor peribadi dan keluarga, faktor pendidikan serta peranan kerajaan dalam memperkasakan perniagaan dalam talian. Selain itu, faktor penglibatan lain yang mempengaruhi adalah populariti kerana perniagaan dalam talian memberikan pelbagai kemudahan kepada penggunanya serta merupakan salah satu medium penciptaan keuntungan dengan cepat. Penulis berpendapat faktor-faktor yang didedahkan dalam kajian lepas merupakan pendorong kepada peningkatan peniaga wanita Melayu di Malaysia.

Kesinambungan daripada dapatan faktor yang menjadi kejayaan kepada peniaga dalam talian adalah keupayaan membina dan memantapkan jalinan hubungan sosial dengan pelanggan, ejen, pembekal dan pesaing, mempunyai sifat-sifat keusahawanan seperti kreatif, keazaman dan keupayaan, menunjukkan integriti dan bijak mencari peluang. Namun begitu, dapatan menunjukkan kegagalan pula disebabkan oleh personaliti peniaga seperti tiada keyakinan diri untuk berhadapan dengan cabaran perniagaan, dilema antara kerjaya dan kehidupan peribadi, tidak dapat menangani permasalahan persekitaran, lemah dan kabur dalam bidang yang diceburi serta kaedah pemasaran 
yang tidak betul. Justeru, penulis berpendapat dalaman individu merupakan elemen penting dalam menjadikan sama ada peniga wanita dalam talian berjaya/gagal dalam perniagaan yang diceburi.

Hasil sorotan literatur berkaitan cabaran mendapati aspek pasaran seperti kehadiran produk-produk tiruan mengganggu perniagaan dalam talian yang dijalankan. Selain itu, cabaran memperkenalkan produk kepada pelanggan juga terpaksa didepani oleh peniaga yang baru memulakan perniagaan, risiko keuntungan/kerugian, kaedah pemasaran yang betul dan juga pesaing yang ramai dalam memasarkan perniagaan dalam talian. Oleh itu, penulis berpendapat, peniaga wanita dalam talian perlu selalu menambah ilmu berkaitan kaedah perniagaan dalam talian yang betul dan efektif supaya dapat mengekalkan dan mengembangkan perniagaan yang dijalankan.

Sebagai tambahan, dapatan kajian lepas berkaitan skim sokongan mendedahkan pelbagai inisiatif telah dijalankan oleh pihak berwajib bagi membantu meningkatkan mutu perniagaan dalam talian dalam kalangan peniaga wanita Melayu. Natijahnya, pelbagai kesan positif kesan penyertaan dalam skim sokongan ini kerana peniaga dapat mengurangkan beban kewangan dan meningkatkan ilmu berkaitan perniagaan dalam talian. Justeru, penulis menyimpulkan bahawa peranan pihak berwajib dalam mewujudkan skim sokongan ini amat perlu bagi membantu peniaga dalam talian dan pada waktu yang sama dapat meningkatkan ekonomi di Malaysia.

Rentetan daripada aspek tingkah laku perniagaan dalam talian, pelbagai landasan teori yang diaplikasikan dalam kajian bidang perniagaan menunjukkan ianya saling berkait. Teori tindakan bertujuan (TORA) dan teori tingkah laku terancang (TPB) dapat menjawab persoalan berkaitan sebab penglibatan dan faktor kejayaan/kegagalan. Sebagai tambahan, teori UTAUT dan Model AIDA pula dapat dikaitkan dengan penggunaan dan teknik pemasaran perniagaan dalam talian. Oleh itu, penulis berpendapat, teori yang dinyatakan dapat memberikan pencerahan berkaitan aspek-aspek tingkah laku bagi perniagaan dalam talian.

\section{Kesimpulan}

Peniaga wanita Melayu dilihat sebagai golongan yang dominan dalam penyertaan perniagaan secara talian. Perbincangan mengenai kajian lepas dan landasan teori dalam bidang perniagaan secara talian mendedahkan mengenai impak perniagaan secara talian kepada masyarakat terutamanya dalam kalangan peniaga wanita Melayu. Justeru, kajian ini dapat memberikan maklumat pengenalan berkaitan perniagaan secara talian sebagai pengetahuan umum kepada penyelidik dan masyarakat.

\section{Rujukan}

Abdullah \& Mohd Shahrir. (2015). Faktor-faktor yang mempengaruhi pelajar-pelajar Diploma Kejuruteraan Politeknik dalam menceburi bidang keusahawanan. Master Dissertation, Universiti Tun Hussein Onn Malaysia.

Ahmad Firdause Fadzil \& Mohd Rafi Yaacob. (2014). Faktor Individu sebagai Komponen Menyumbang kepada Penciptaan Perniagaan Baharu Usahawan e-Dagang Prosiding PERKEM 9.

e ISSN 2735 - 1904

https://doi.org/10.22452/JOMAS.vol31no1.5 
Ajzen, I. (1991). The theory of planned behavior. Organizational behavior and human decision processes, 50 (2), 179-211.

Azilahwati Adam, Syaharizad Abdul Razak \& Intan Shazila Samsudin. (2014). Pembangunan Keusahawanan dari Perspektif Kolej Komuniti. Prosiding Seminar Antarabangsa Kelestarian Insan 2014 (INSAN 2014). Batu Pahat, Johor.

Bergh, L. (2013). Sustainability-driven entrepreneurship: perceptions of challenges and obstacles in a South African context. Master Dissertation. University of Cambridge.

Chang H. J. (2010). Institutions and Economic Development: Theory, Policy and History Journal of Institutional Economics, 1-26.

Fan, Y., A. Saliba, E.A. Kendall \& J. Newmarch. (2005). Speech interface: An enhancer to the acceptance of m-commerce application. Proceedings of the International Conference on Mobile Bus.

Ferrell. O. C. \& Michael D. H. (2005). Marketing Strategy (4 ed.). Thompson: South Western.

Fishbein, M., \& Ajzen, I. (1980). Understanding attitudes and predicting social behaviour. Englewood Cliffs, N.J.: Prentice-Hall.

Kreitner, Kinicki. (2010). Organizational Behavior. New York: McGraw-Hill.

Lai, K. P., Robert J. N., Khong S.T., \& Boon B. C. (2010). Effect of innovation to thesuccess of female entrepreneurs. Journal of innovation management in small and medium enterprises.

Lope Pihie, Zaidatol Akmaliah \& Hassan Hisyamuddin. (2010). Memperkasa tekad keusahawanan pelajar. Serdang: Penerbit Universiti Putra Malaysia.

Mohd Azrone Sarabatin. (2011). E-Dagang Perkasa Kerjaya Keusahawanan. Berita Harian, 17.

Muhammad Rafiq Abdullah Husmin, Safura Ahmad Sabri, Hazlin Falina Rosli, Nurzakira Afnee Zakaria, Mohammad Aizham Mohammad Kassim, \& AhmadFatin Mohamad Suhaimi. (2016). Usahawan Mikro Kredit: Faktor-faktor dalaman yang mendorong kejayaan perniagaan. Proceeding of the $2^{\text {nd }}$ International Conference on Economics \& Banking 2016 (2nd ICEB).

Nazrolnizah, M. N., Nubli, M., \& Wahab, A. (2014). Pengukuran Sifat Bersungguh Sungguh Menggunakan Teknik Biofeedback di Kalangan Usahawan Wanita. 1

Nik Rahim Nik Rajis. (2016). E-dagang Menurut Perspektif Islam. Conference Paper Researchgate.

Norizan Razak \& Zaharah Hassan. (2010). Developing Women e-Entrepreneurs: A Malacca Case Study. Persidangan Rural ICT Development 3rd National Conference on Rural ICT Development: Empowering Rural Communities Through Broadband Initiatives. Sintok. Kedah: Malaysia.

Nor Fazilah Noor Din \& Hishamudin Isam. (2019). Tema Perbualan Remaja Malaysia Dalam Facebook. Jurnal Pengajian Melayu/Journal of Malay Studies (JOMAS), 30 (1), 137- 166.

e ISSN 2735 - 1904

https://doi.org/10.22452/JOMAS.vol31no1.5 
Norhayati Ab. Rahman. (2010). Imej Wanita Korporat Dalam Teks Kesusasteraan Melayu Moden Malaysia: Daripada Lensa Pengarang Wanita. Jurnal Pengajian Melayu/Journal of Malay Studies (JOMAS), 21 (1), 196- 211.

Nor Hayati Sa'at \& Abdul Rahman Embong. (2015). Pemerkasaan golongan ibu tunggal melalui Program Usahatani Cendawan di Terengganu. Journal of Borneo Social Transformation Studies (JOBSTS), 1(1).

Nurdin, G., Chan, G. K., Selvadurai, S., \& Ishak, S. (2014). Hubungan sosial dan p e r n i a g a a $n$ kecil-kecilan di Malaysia-Tingkah laku inovatif usahawan wanita atas talian. Geografia: Malaysian Journal of Society and Space, 10(6), 206-218.

Nurdin, Gusniar, Geraldine K.L Chan, Sivapalan S, \& Suraiya Ishak. (2017). Hubungan sosial dan perniagaan kecil-kecilan di Malaysia-Tingkah laku inovatif usahawan wanita atas talian. Geografia-Malaysian Journal of Society and Space. 10 (6).

Othman, Norasmah, Hashim, Norashidah Ab Wahid \& Hariyaty. (2012). Readinesstowards entrepreneurship education: Students and Malaysian Universities. Education + Training. 54.

Ott, B., \& Mack, R. (2014). Introducing Critical Media Studies ( $2^{\text {nd }}$ ed.). Missouri State University: John Wiley \& Sons, Inc.

Rosmiza Mohd Zainol, Amriah Buang, Rosniza Aznie Che Rose, Jabil Map Jabil \& Mazdi Marzuki. (2015). Penilaian faktor institusi dalam menentukan kemampanan usahawan jerami padi. Malaysia. Journal of Society and Space, 11 (4). 140 - 151.

Ruslan Romli \& Norazuwa Mat. (2016). Faktor kebergunaan dan kemudahgunaan terhadap niat penggunaan e-dagang di kalangan industri kecil dan sederhana di Sabah. Kolej Perniagaan UUM: Universiti Utara Malaysia.

Sharulnizam Ramli, Syed Alwi Syed Abu Bakar \& Sabzali Musa Khan. (2015). Cabaran yang Dihadapi Pendidikan Seni Visual Dengan Kemunculan Teknologi Maklumat Dan Komunikasi (ICT) Di Malaysia. Jurnal Pengajian Melayu/Journal of Malay Studies (JOMAS), 26 (1), 81-93.

Siti Masayu Rosliah Abdul Rashid. (2016). Keupayaan ICT Dalam Meningkatkan P e n c a p a i a n Usahawan Wanita: Satu Kajian Kes Usahawan Luar Bandar Di Malaysia. Journal of Social Science and Humanities.11 (2). 078-103.

Suriatie Mohd Yunus \& Nor Aishah Buang. (2017). Pendekatan penggunaan medium e-pemasaran dalam kalangan usahawan wanita. Journal of Global Business and Social Entrepreneurship. 1 (1), 47 - 57.

Turban, E. \& King, D. (2003). Introduction to E-Commerce. New York, London: Springer.

Ummi Munirah Syuhada Mohamad Zan, Mohamad Rizki Moi, Aidatul Najwa HarunArrosyid. \& Wan Suraya Wan Hassin. (2017). Faktor-Faktor yang Mempengaruhi Kejayaan Usahawan Wanita Tekun: Satu Kajian di Daerah Hulu Langat. Conference: 4th International Conference on Management and Muamalah 2017 (ICoMM 2017).

Venkatesh, V., Morris, M. G., Davis, G. B., \& Davis, F. D. (2003). User acceptance of information technology: Toward a unified view. MIS quarterly, 425-478.

e ISSN 2735 - 1904

https://doi.org/10.22452/JOMAS.vol31no1.5 